\title{
Effects of Eleutheroside B and Eleutheroside E on activity of cytochrome P450 in rat liver microsomes
}

\author{
Sixun Guo ${ }^{1 \dagger}$, Yan Liu ${ }^{1 \dagger}$, Zhiping Lin', Sheng Tai ${ }^{2}$, Shuo Yin ${ }^{1}$ and Gaofeng Liü ${ }^{1 *}$
}

\begin{abstract}
Background: Chemicals of herbal products may cause unexpected toxicity or adverse effect by the potential for alteration of the activity of CYP450 when co-administered with other drugs. Eleutherococcus senticosus (ES), has been widely used as a traditional herbal medicine and popular herbal dietary supplements, and often co-administered with many other drugs. The main bioactive constituents of ES were considered to be eleutherosides including eleutheroside B (EB) and eleutheroside $E$ (EE). This study was to investigate the effects of EB and EE on CYP2C9, CYP2D6, CYP2E1 and CYP3A4 in rat liver microsomes in vitro.

Method: Probe drugs of tolbutamide (TB), dextromethorphan (DM), chlorzoxazone (CLZ) and testosterone (TS) as well as eleutherosides of different concentrations were added to incubation systems of rat liver microsomes in vitro. After incubation, validated HPLC methods were used to quantify relevant metabolites.

Results: The results suggested that EB and EE exhibited weak inhibition against the activity of CYP2C9 and CYP2E1, but no effects on CYP2D6 and CYP3A4 activity. The IC 50 values for EB and EE were calculated to be $193.20 \mu \mathrm{M}$ and $188.36 \mu \mathrm{M}$ for CYP2E1, $595.66 \mu \mathrm{M}$ and $261.82 \mu \mathrm{M}$ for CYP2C9, respectively. Kinetic analysis showed that inhibitions of CYP2E1 by EB and EE were best fit to mixed-type with Ki value of $183.95 \mu \mathrm{M}$ and $171.63 \mu \mathrm{M}$, respectively.

Conclusions: These results indicate that EB and EE may inhibit the metabolism of drugs metabolized via CYP2C9 and CYP2E1, and have the potential to increase the toxicity of the drugs.
\end{abstract}

Keywords: Eleutheroside B, Eleutheroside E, Cytochrome P450, In vitro

\section{Background}

Eleutherococcus senticosus (ES, Acanthopanax senticosus), also called Siberian ginseng in the Siberian Taiga region and Ciwujia in China, belongs to the family of Araliaceae, are mainly distributed in the far-eastern region of Russia, the northeastern of China, Japan and Korea. It is a medicinal herb that dates back more than 2000 years according to Chinese medicine records and is also known as a powerful tonic herb with an impressive range of health benefits. This medicinal plant is not only popular in China and Russia, but also one of the 10 popular herbal dietary supplements used in the United States [1]. Recently, ES has drawn increasingly attention

\footnotetext{
*Correspondence: liugaofengwty@126.com

'Equal contributors

'Department of Pharmacy, the Second Affiliated Hospital of Harbin Medical University, Harbin 150086, China

Full list of author information is available at the end of the article
}

due to its excellent effects on invigorating spleen, benifitting liver and nourishing kidney [2], and lots of chemical, pharmacological and clinical studies on ES have been carried out all over the world [3,4]. The main bioactive constituents of ES were considered to be eleutherosides including eleutheroside $B$ (EB) and eleutheroside $\mathrm{E}$ (EE) (Figure 1). As the quality standard of ES, the amount of EB and EE should be more than $0.8 \%$ according to the "United States pharmacopoeia" and "European pharmacopoeia" [5]. EB possessed antistress, anti-fatigue [6], anti-oxidant [7], anti-irradiation, anti-gastric ulceration, anti-inflammatory [8], immunopotentiating [9], immunomodulatory [10], anti-diabetic effects $[11,12]$ etc. Besides, EB and EE showed obvious protective effects against neuritic atrophy and nerve cell death $[13,14]$. Furthermore, EE exerted significant antiinflammatory effects by suppressing the gene expression

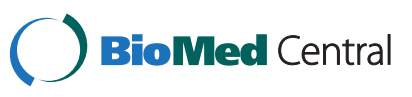




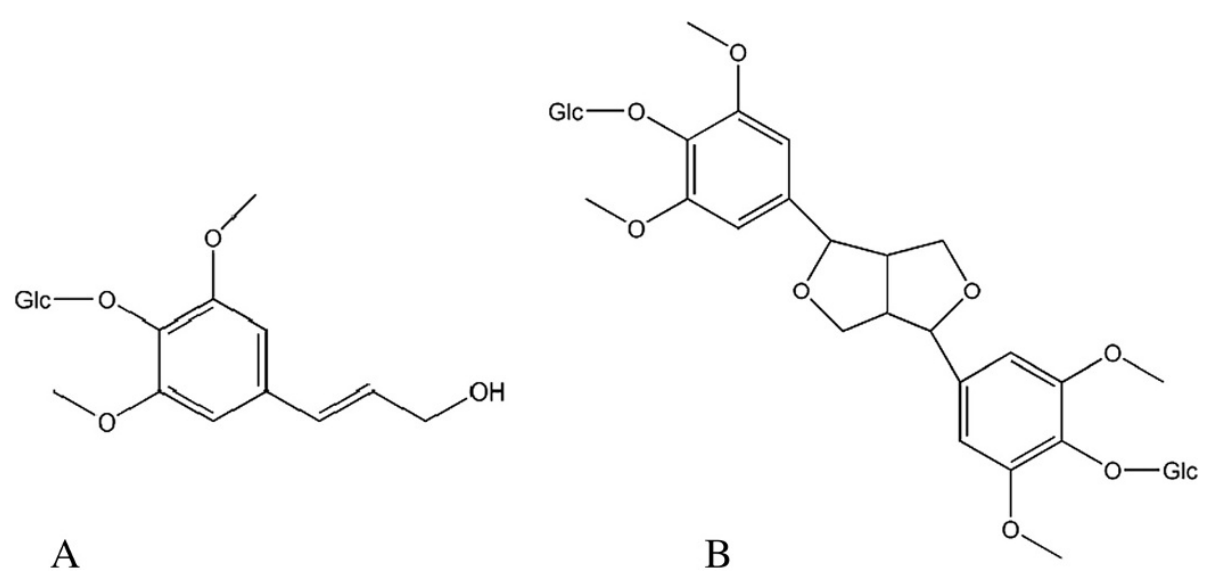

Figure 1 Chemical structures of eleutheroside B and eleutheroside E. Glc are connected by $\beta$-D-glycosidic linkages. (A) Eleutheroside B (B) Eleutheroside $\mathrm{E}$

of inflammatory proteins and protective effects in ischemia heart [15]. In addition, EE has the potential abilities to alleviate behavioral alterations induced by sleep deprivation [16] and fatigue both in physical and mental fatigue [17].

Cytochrome P450 (CYP450), the most important drug-metabolizing enzymes, with largest number and highest abundance of CYP isoforms present in the liver. It is well known that CYP450 play a vital role in the metabolism of currently used drugs. Most drugs are metabolized through several major CYP isoforms. CYP3A4, CYP2D6, CYP2C9 and CYP2E1 have been estimated to be involved in the metabolism of approximately $85 \%$ of the drugs in clinical practice [18]. Since these subtypes metabolize numerous drugs, drug-drug interactions (DDIs) can potentially occur when multiple drugs are co-administered. Therefore, evaluation of effects on CYP isoforms of drugs is important for the prediction of potential DDIs. Inhibition of CYP450 enzymes is the most important reason caused DDIs, which raises the toxicity of drugs.

To our knowledge, this is the first study focus on the potential role of EB and EE in CYP450-mediated DDIs. The present study was performed to investigate the influence of EB and EE on the activities of CYP2C9, CYP2D6, CYP2E1 and CYP3A4 in rat liver microsomes and the mechanisms in vitro, which could be used to predict the probability of herb-drug interactions, providing references for correlation studies and decrease the risk of drug use.

\section{Methods}

\section{Chemicals and reagents}

Tolbutamide was purchased from Dr. Ehrenstorfer $\mathrm{GmbH}$ (Augsburg, Germany). 4-hydroxytolbutamide and 6-hydroxychlorzoxazone were obtained from Toronto
Research Chemicals Inc. (North York, Canada). Dextromethorphan, dextrorphan and chlorzoxazone were supplied by Sigma-Aldrich Co. (St Louis, MO, USA). Testosterone was obtained from International Laboratory Limited (San Bruno, CA, USA). 6 $\beta$-hydroxytestosterone was purchased from BD Biosciences Co. (Woburn, MA, USA). Phenacetin, cortisone acetate, EB and EE were from National Institute for the Control of Pharmaceutical and Biological Products (Beijing, China). NADPH was obtained from Roche Diagnostics GmbH (Mannheim, Germany). All other reagents were of HPLC or analytical grade.

\section{Preparation of rat liver microsomes}

Wistar rats (180 $\pm 20 \mathrm{~g}$, male) were supplied by the Animal Experimental Center of Harbin Medical University (Harbin, China), which was fully accredited by the Guide for the Care and Use of Laboratory Animals of the National Institutes of Health. The protocol was approved by the Committee on the Ethics of the Harbin Medical University (Permit Number: HMUIRB20120011), and the rats were handled in a manner that met all the recommendations formulated by the National Society for Medical Research and Guidelines for the Care and Use of Laboratory Animals. Rat liver microsomes were prepared from liver tissue by differential ultra-centrifugation [19], packed and stored at $-80^{\circ} \mathrm{C}$ for further analysis. These operations were carried out in the ice. Protein concentrations of the microsomes were determined by the method of Bradford [20].

\section{Cytochrome $\mathrm{P} 450$ probe substrate assays} Tolbutamide and 4-methyhydroxylation assay for CYP2C9

The incubation system of CYP2C9 in vitro contained phosphate buffer (100 mM, pH7.4), liver microsomal protein $\left(0.5 \mathrm{mg} \cdot \mathrm{mL}^{-1}\right), \mathrm{MgCl}_{2}(10 \mathrm{mM})$, tolbutamide 
$(90 \mu \mathrm{M})$ and eleutherosides in a final volume of $200 \mu \mathrm{L}$. Pre-incubated $5 \mathrm{~min}$, the reaction was initiated by adding NADPH (1 $\mathrm{mM}$ concentration in incubation) and the incubation systems were incubated at $37^{\circ} \mathrm{C}$ for $60 \mathrm{~min}$. After incubation, $50 \mu \mathrm{L}$ ice-cold acetonitrile was added to terminate the reaction, and phenacetin of a final concentration $20 \mu \mathrm{M}$ was added as internal standard. With 5 min suspension, the mixture was centrifuged for $30 \mathrm{~min}$ at $12000 \mathrm{r} \cdot \mathrm{min}^{-1}$. The supernatant of $20 \mu \mathrm{L}$ was analyzed by the Waters HPLC system 2010 (Waters, USA, with 600 pump, 996PAD UV detector and Millipore Systems). Tolbutamide, 4-hydroxytolbutamide and phenacetin were separated on a Diamonsil $\mathrm{C}_{18}$ reverse phase column $(5 \mu \mathrm{m}, 4.6 \mathrm{~mm} \times 200 \mathrm{~mm})$. The column temperature was set to $35^{\circ} \mathrm{C}$. The mobile phase, at a flow rate of $1 \mathrm{~mL} \cdot \mathrm{min}^{-1}$, consisted of methanol and $0.1 \%$ acetic acid $(55: 45, \mathrm{v} / \mathrm{v})$. UV detection was at wavelength of $229 \mathrm{~nm}$. The organic solvent which is at low concentration $(\leq 0.5 \%)$ in all incubation systems wouldn't affect the activity of enzymes. The yield of corresponding metabolites was calculated by referring to a standard curve constructed based on known concentrations of the pure metabolites.

\section{Dextromethorphan and O-demethylation assay CYP2D6}

Incubation conditions were the same as Section Tolbutamide and 4-methyhydroxylation assay for CYP2C9. The liver microsomal protein was $1.0 \mathrm{mg} \cdot \mathrm{mL}^{-1}$ and tolbutamide was replaced by $25 \mu \mathrm{M}$ dextromethorphan. Reactions were terminated by $80 \mu \mathrm{L}$ ice-cold acetonitrile and internal standard phenacetin (final concentration of $50 \mu \mathrm{M})$ was added, the denatured protein was removed by centrifuged at $12000 \mathrm{r} \cdot \mathrm{min}^{-1}$ for $30 \mathrm{~min}$. The supernatant of $20 \mu \mathrm{L}$ was injected into the HPLC system, with the mobile phase of methanol, water, phosphate and triethylamine (42:58:0.15:0.3, v/v/v/v) at a flow rate of $1 \mathrm{~mL} \cdot \mathrm{min}^{-1}$, detection was at wavelength of $280 \mathrm{~nm}$.

\section{Chlorzoxazone and 6-hydroxylation assay for CYP2E1}

Each incubation mixture $(200 \mu \mathrm{L})$ included liver microsomal protein (0.75 mg. $\left.\mathrm{mL}^{-1}\right), \mathrm{MgCl}_{2}(10 \mathrm{mM})$ in $100 \mathrm{mM}$ phosphate buffer (pH7.4) and $25 \mu \mathrm{M}$ chlorzoxazone. With 5 min pre-incubation, all reactions were initiated by addition of NADPH $(1 \mathrm{mM})$ and were carried out in $37^{\circ} \mathrm{C}$ water bath for $30 \mathrm{~min}$, and then were stopped by addition of $150 \mu \mathrm{L}$ ice-cold acetonitrile and internal standard ( $80 \mu \mathrm{M}$ phenacetin). After centrifugation at $12000 \mathrm{r} \cdot \mathrm{min}^{-1}$ for $30 \mathrm{~min}, 20 \mu \mathrm{L}$ of the supernatant was injected into the HPLC system, and eluted with methanol-water (47:53) at a flow rate of $1.0 \mathrm{~mL}$. $\mathrm{min}^{-1}$, UV absorbance was monitored at $287 \mathrm{~nm}$.

\section{Testosterone and $6 \beta$-hydroxylation assay for CYP3A4}

Testosterone solution (in methanol, final concentration of $100 \mu \mathrm{M}$ ) was evaporated to dryness under nitrogen in $40^{\circ} \mathrm{C}$ water bath, then additional reagents were added to give a final incubation volume of $200 \mu \mathrm{L}$ : liver microsomal protein $\left(0.5 \mathrm{mg} \cdot \mathrm{mL}^{-1}\right)$ in $50 \mathrm{mM}$ sodium phosphate buffer (pH7.4) and $\mathrm{MgCl}_{2}(10 \mathrm{mM})$. Following a 5 min pre-incubation, reactions were started with addition of NADPH (1 mM). Following $30 \mathrm{~min}$ incubations at $37^{\circ} \mathrm{C}$, reactions were stopped with organic solution $(280 \mu \mathrm{L}$ ice-cold acetonitrile), and cortisone acetate was added as internal standard with final concentration of $12.5 \mu \mathrm{M}$. The mixture was centrifugated at $12000 \mathrm{r}$. $\mathrm{min}^{-1}$ for $30 \mathrm{~min}$, and the supernatant of $20 \mu \mathrm{L}$ was injected into the HPLC, with UV detection at $245 \mathrm{~nm}$. Mobile phase consisted of methanol and water (65:35, $\mathrm{v} / \mathrm{v}$ ), and the flow rate was $1.0 \mathrm{~mL} \cdot \mathrm{min}^{-1}$.

\section{Determination of $\mathrm{K}_{\mathrm{m}}$ and $\mathrm{V}_{\max }$}

The apparent $K_{m}$ (Michaelis constant) and $V_{\max }$ (maximum reaction velocity) values were determined in a range of concentrations of probe drugs. The concentrations were as follows: tolbutamide 3.5 600.0 $\mu \mathrm{M}$, dextromethorphan 3.5 400.0 $\mu \mathrm{M}$, chlorzoxazone 5.0 300.0 $\mu \mathrm{M}$, and testosterone $12.5 \sim 500.0 \mu \mathrm{M}$. The other incubation conditions were the same as Section Cytochrome P450 probe substrate assays.

\section{Determination of effects of EB and EE on CYP450 activity}

To evaluate whether EB and EE affect the activity of CYP450, the probe substrate reaction assays were performed with EB or EE at concentrations of 0, 2, 10, 25, 50, 150, $300 \mu \mathrm{M}$ under the conditions described earlier, with triplicate incubations for each concentration. The concentrations of respective probe substrates were selected according to $\mathrm{K}_{\mathrm{m}}$ established in the enzyme kinetic assays described above. The $\mathrm{IC}_{50}$ values (concentration of inhibitor causing $50 \%$ inhibition of enzyme activity) were determined based on the concentration-inhibition curves.

\section{Assay for enzymatic kinetic parameters}

The exact inhibition constants ( $K_{i}$ values) were measured and the modes of inhibition were determined for the components exhibiting $\mathrm{IC}_{50}$ values of less than $200 \mu \mathrm{M}$. The $K_{i}$ values were determined in a range of concentrations of probe substrates (approximately $\mathrm{K}_{\mathrm{m}} / 2, \mathrm{~K}_{\mathrm{m}}, 2 \mathrm{~K}_{\mathrm{m}}$ and $4 \mathrm{~K}_{\mathrm{m}}$ ) and different concentrations of $\mathrm{EB}(0,100,200,300 \mu \mathrm{M})$ and $\operatorname{EE}(0,100,200,300 \mu \mathrm{M})$. Dixon and Lineweaver-Burk plots and the second plots showed the data graphically for interpretation of inhibition mode. All experiments were separately performed in three times.

\section{Results}

\section{Enzymatic kinetic parameters for CYP450 in rat liver} microsomes

The apparent $K_{m}$ values for tolbutamide 4-methyhydroxy lation, dextro- methorphan O-demethylation, chlorzoxazone 
6-hydroxylation and testosterone 6 $\beta$-hydroxylation in rat liver microsomes were 94.80, 29.07, 30.42 and 103.81 $\mu \mathrm{M}$, respectively. The $\mathrm{V}_{\max }$ values for tolbutamide 4methyhydroxylation, dextromethorphan O-demethylation, chlorzoxazone 6-hydroxylation and testosterone 6 $\beta$ hydroxylation in liver microsomes were 1.57, 0.28, 0.05 and $2.71 \mathrm{nmol} / \mathrm{min} / \mathrm{mg}$ protein, respectively.

\section{$\mathrm{IC}_{50}$ for $\mathrm{EB}$ and $\mathrm{EE}$ inhibition}

The inhibitory potency of EB and EE were determined based by the concentration-inhibition curves of the four CYP isoforms. As shown in Figure 2, EB inhibited tolbutamide 4-methyhydroxylation (CYP2C9) with an $\mathrm{IC}_{50}$ of $595.66 \mu \mathrm{M}$ and chlorzoxazone 6-hydroxylation (CYP2E1) with an $\mathrm{IC}_{50}$ of $193.20 \mu \mathrm{M}$. The $\mathrm{IC}_{50}$ values of EE were $261.82 \mu \mathrm{M}$ for CYP2C9 and $188.36 \mu \mathrm{M}$ for CYP2E1 (Figure 2), respectively. The results indicated that $\mathrm{EB}$ and $\mathrm{EE}$ can inhibit CYP2E1 and CYP2C9 activities in rat liver microsomes. On the other hand, EB and EE did not cause inhibition of CYP2D6, CYP3A4, the $\mathrm{IC}_{50}$ values could not be extrapolated and calculated.

\section{Type of inhibition of CYP2E1 by EB and EE}

To further characterize the inhibition of CYP2E1 activity by $E B$ and $E E, K_{i}$ values were calculated and the inhibition type were determined with $\mathrm{EB}$ and EE concentrations of 0, 100, 200, $300 \mu \mathrm{M}$. Dixon and LineweaverBurk plots showed that the inhibition of EB to CYP2E1 was best fit to a mixed-type, and the $K_{i}$ value was evaluated to be $183.95 \mu \mathrm{M}$ from the secondary plot of the slopes of Lineweaver-Burk plots versus the concentrations of EB (Figure 3). Furthermore, kinetic study of the effect of EE on CYP2E1 enzyme showed that the inhibition was mixed-type with $K_{i}$ of $171.63 \mu \mathrm{M}$ (Figure 4).

\section{Discussion}

The incubation experiment of liver microsomes is a generally used method for drug metabolism in vitro, which is recommended by the relevant guidelines of the United States [21]. The liver microsomes consist of a variety of enzymes, and we chose tolbutamide, dextromethorphan, chlorzoxazone and testosterone, which are extensively used as probe substrates for CYP2C9, CYP2D6, CYP2E1 and CYP3A4 respectively in this study [22-25].

The present study addressed that EB and EE exhibited weak inhibition against rat CYP2C9, CYP2E1 activity, and no effect on CYP2D6 and CYP3A4 activity in rat liver microsomes in vitro. The $\mathrm{IC}_{50}$ values of $\mathrm{EE}$ and $\mathrm{EB}$ were $193.20 \mu \mathrm{M}$ and $188.36 \mu \mathrm{M}$ for CYP2E1, and $595.66 \mu \mathrm{M}$ and $261.82 \mu \mathrm{M}$ for CYP2C9, respectively. Kinetic analysis suggested that the inhibition of CYP2E1 by $E B$ was best fit to a mixed-type with $K_{i}$ value of $183.95 \mu \mathrm{M}$, while the inhibition of CYP2E1 by EE was also best fit to a mixed manner with $K_{i}$ value of $171.63 \mu \mathrm{M}$. Consistently, Donovan et al assessed the influence of standardized extracts of ES on the activity of CYP2D6 and CYP3A4 in normal volunteers, and found that there were no statistically significant differences in the pharmacokinetic parameters determined by noncompartmental modeling, indicating that ES are unlikely to significantly affect CYP3A4 and CYP2D6 activities [26].

Our results suggest that EB and EE have inhibition effects on CYP2C9 and CYP2E1 in rat hepatic microsomes. Studies show that the extrapolation of CYP2E1 between species appears to be quite well, and rat seems to be best model for human in this respect [27]. Based on the metabolic substrate studies, human CYP2C9 corresponds to rat $\mathrm{CYP} 2 \mathrm{C} 11$, which has quite similar metabolic substrate with human CYP2C9 [28].
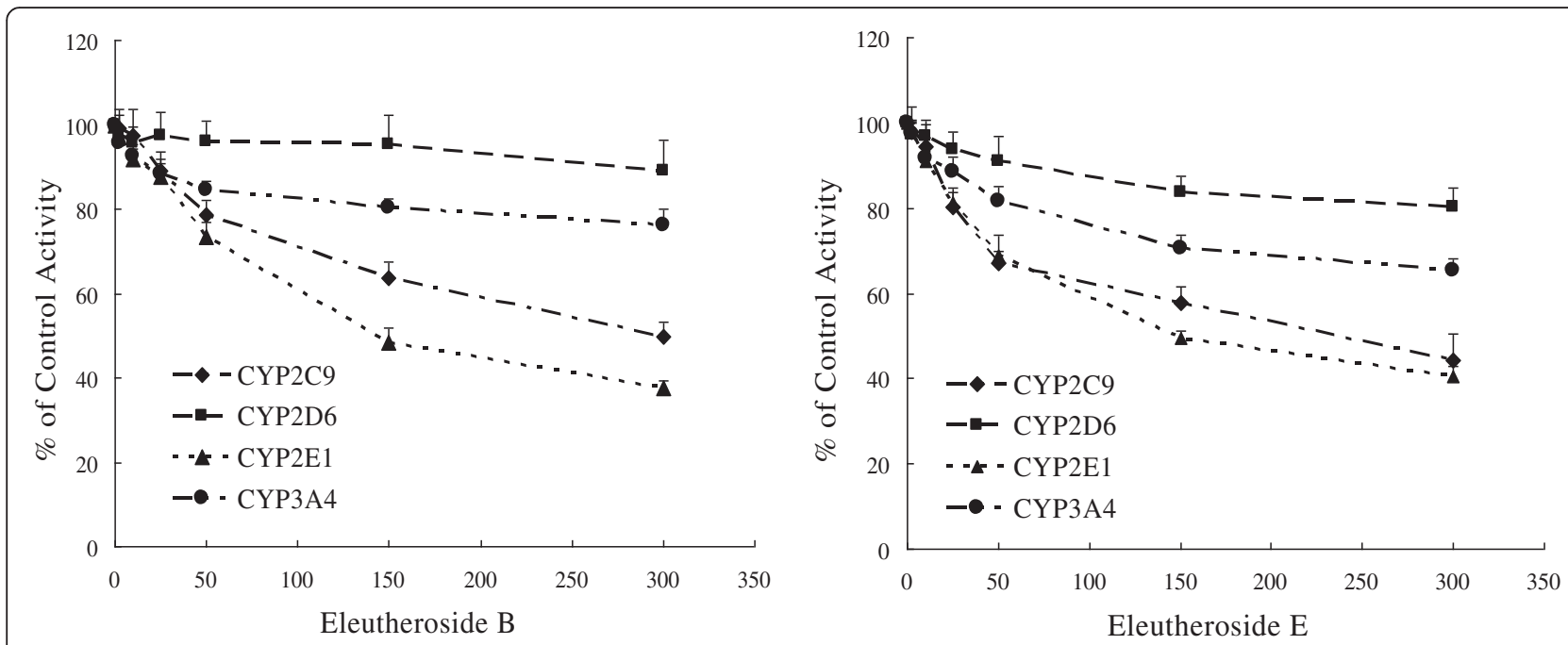

Figure 2 Concentration-inhibition curves of CYP enzymes by EB and EE $(n=3)$. 


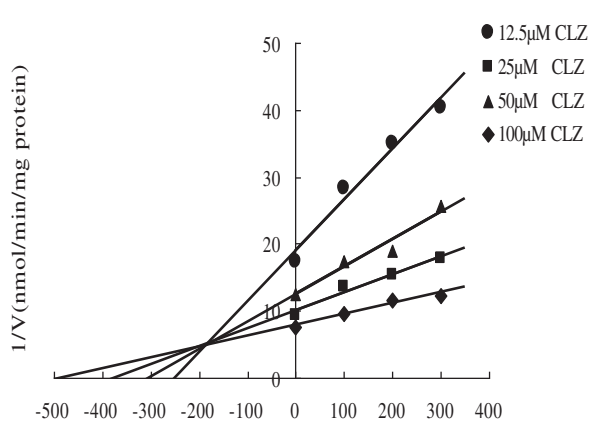

A

Concentration of $\mathrm{EB}(\mu \mathrm{M})$

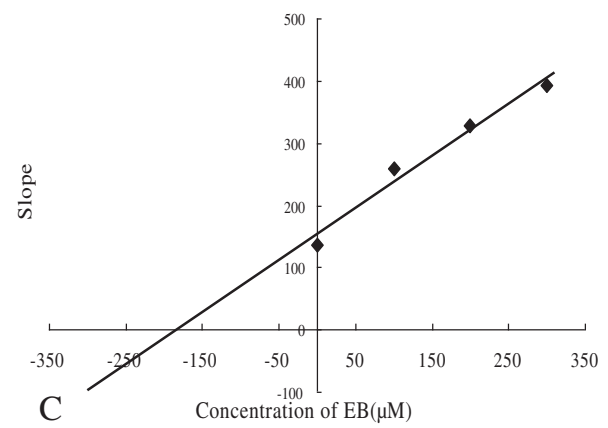

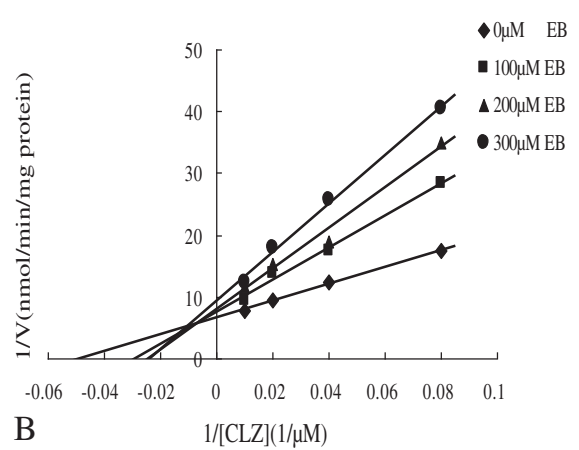

B $\quad 1 /[$ CLZ] $[1 / \mu \mathrm{M})$

Figure 3 Kinetic study of the effect of EB on CYP2E1 enzyme (A) Dixon plot of inhibition effect of EB on chlorzoxazone 6-hydroxylation (CYP2E1). (B) Lineweaver-Burk plot of inhibitory effect of EB on chlorzoxazone 6-hydroxylation (CYP2E1). (C) Secondary plot of the slopes from Lineweaver-Burk plot vs EB concentrations. Each data point represents mean of triplicate incubations.
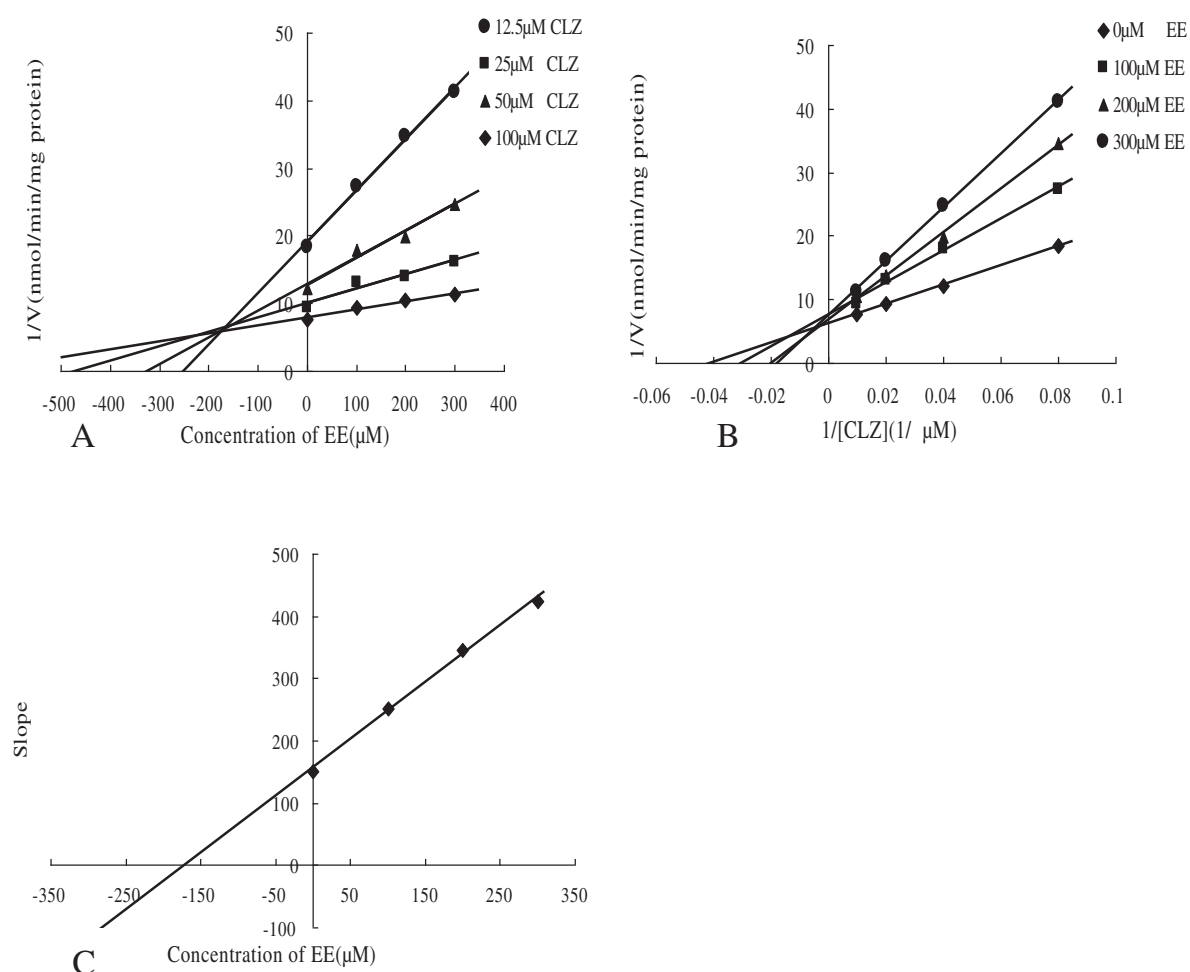

Figure 4 Kinetic study of the effect of EE on CYP2E1 enzyme. (A) Dixon plot of inhibition effect of EE on chlorzoxazone 6-hydroxylation (CYP2E1). (B) Lineweaver-Burk plot of inhibitory effect of EE on chlorzoxazone 6-hydroxylation (CYP2E1). (C) Secondary plot of slopes from Lineweaver-Burk plot versus EB concentrations. Each data point represents mean of triplicate incubations. 
CYP2C9 metabolizes more than $10 \%$ of drugs clinically used, including antidepressants, hypoglycemics, angiotensin II blockers, non-steroidal anti-inflammatory drugs, S-warfarin, diclofenac, tolbutamide, glipizide, losartan, flurbiprofen, naproxen, ibuprofen, fluoxetine, sertraline, valproate, phenobarbital, phenytoin, fluvastatin, tamoxifen, etc $[16,28]$. CYP2E1 also plays an important role in the metabolism of many commonly pharmaceuticals including nifedipine, erythromycin, acetaminophen, enflurane, ethanol and halothane $[16,28]$. The inhibition can result in the increase of the plasma concentration and toxicity of concomitant drugs, especially for those with narrow therapeutic windows such as warfarin, phenobarbital and phenytoin. More attention should be paid when ES is used with these drugs concomitantly. However, further clinical investigation should be carried on to prove whether inhibitions by EB and EE on CYP2C9 or CYP2E1 may alter the pharmacokinetics of these drugs and increase their adverse drug reactions when they are co-administered with ES.

Previous studies have shown that concomitant administration of herbal preparations and pharmaceuticals may affect drug metabolism and significantly increase the risk of serious adverse reactions. For instance, the interaction between warfarin and St. John's wort have been reported and the mechanism by which St. John's wort activates CYP450 enzymes is possibly the most thoroughly researched idea [29]. In addition, a number of the clinical relevance of herb interactions has been reported, touching on interactions of Salvia (Danshen), Flos carthami, Centella asiatica, Andrographis paniculata, Silybum marianum, Acorus calamus and Goldenseal with various CYP450 isoforms [30-36]. ES has been widely used as a traditional herbal medicine and popular herbal dietary supplements, and often co-administered with many other drugs [37-41], the present study may facilitate predicting possible herb-drug interactions when ES is used in combination with other drugs, and decrease the incidence of the CYP450-mediated interactions.

\section{Conclusion}

In conclusion, $\mathrm{EB}$ and $\mathrm{EE}$ inhibit $\mathrm{CYP} 2 \mathrm{C} 9$ and CYP2E1 activity, but have no effect on CYP2D6 and CYP3A4 in rat liver microsomes in vitro. Both compounds show mixed-type inhibition of CYP2C9 and CYP2E1. The results suggest that both EB and EE could cause potential drug-drug interactions with drugs that are metabolized by CYP2C9 and CYP2E1. However, the inhibitory effects of $\mathrm{EB}$ and $\mathrm{EE}$ on both CYPs were relatively weak and further investigation is needed to evaluate whether the weak inhibitory effects of both compounds on the two CYP450 isoforms are clinically significant.

\section{Competing interests}

Authors of the paper declare that they have no competing interests, and neither financial competing interests nor Non-financial competing interests exist in relation to the manuscript.

\section{Authors' contributions}

SG and YL carried out the design of the study and the acquisition of HPLC data. ZL and TS participated in the preparation of RLM and the design of relative study. SY participated in statistical analysis. GL was involved in drafting and revising of the manuscript. All authors read and approved the final manuscript.

\section{Acknowledgment}

This work was financially supported by the National Natural Science Foundation of China (81173659) and Natural Science Foundation of Heilongjiang Province (D201044).

\section{Author details}

${ }^{1}$ Department of Pharmacy, the Second Affiliated Hospital of Harbin Medical University, Harbin 150086, China. ${ }^{2}$ Department of General Surgery, the Second Affiliated Hospital of Harbin Medical University, Harbin 150086, China.

Received: 16 July 2013 Accepted: 13 December 2013

Published: 2 January 2014

\section{References}

1. Li T: Siberian ginseng. Horsetechnology 2001, 11:79-84

2. Pharmacopoeia Commission of People's Republic of China: Pharmacopoeia of the People's Republic of China. Beijing: China Medical Science Press; 2010.

3. Drozd J, Sawicka T, Prosińska J: Estimation of humoral activity of Eleutherococcus senticosus. Acta Pol Pharm 2002, 59(5):395-401.

4. Han YM, Shi XQ: The research progress of Eleutherococcus senticosus. J Tradit Chin Med 2011, 1:54-55.

5. Zhu YY, Wei XH: Determination of Eleutheroside B and Eleutheroside $E$ in Acanthopanax senticosus by HPLC-PAD. Chin Pharm J 2011, 16(46):1280-1282.

6. Li C, Wang XY, Hu XW: Determination of eleutheroside $B$ in antifatigue fraction of Acanthopanax senticosus by HPLC. Zhongguo Zhong Yao Za Zhi 2008, 23(33):2800-2802.

7. Lee $S$, Son D, Ryu J: Anti-oxidant activities of Acanthopanax senticosus stems and their lignan components. Arch Pharm Res 2004, 1(27):106-110.

8. Díaz Lanza AM, Abad Martínez MJ, Fernández Matellano L, Recuero Carretero C: Lignan and phenylpropanoid glycosides from Phillyrea latifolia and their in vitro anti-inflammatory activity. Planta Med. 2001, 3(67):219-223.

9. Kapil A, Sharma S: Immunopotentiating compounds from Tinospora cordifolia. J Ethnopharmacol 1997, 2(58):89-95.

10. Cho JY, Nam KH, Kim AR: In-vitro and in-vivo immunomodulatory effects of syringin. J Pharm Pharmacol 2001, 9(53):1287-1294.

11. Niu HS, Liu IM, Cheng JT: Hypoglycemic effect of syringin from Eleutherococcus senticosus in streptozotocin-induced diabetic rats. Planta Med 2008, 2(74):109-113.

12. Niu HS, Hsu FL, Liu IM, Cheng JT: Increase of beta-endorphin secretion by syringin, an active principle of Eleutherococcus senticosus, to produce antihyperglycemic action in type 1-like diabetic rats. Horm Metab Res 2007, 12(39):894-898.

13. Tohda C, Ichimura M, Bai Y: Inhibitory effects of Eleutherococcus senticosus extracts on amyloid beta (25-35)-induced neuritic atrophy and synaptic loss. J Pharmacol Sci 2008, 3(107):329-339.

14. Bai Y, Tohda C, Zhu S: Active components from Siberian ginseng (Eleutherococcus senticosus) for protection of amyloid beta (25-35)induced neuritic atrophy in cultured rat cortical neurons. J Nat Med 2011, 3-4(65):417-423.

15. Tokiwa T, Yamazaki T, Sakurai S: Anti-inflammatory effect of eleutheroside E from Acanthopanax senticosus. Foods Food Ingred J Jpn 2006, 7(211):576-582.

16. Huang LZ, Wei L, Zhao HF: The effect of Eleutheroside $E$ on behavioral alterations in murine sleep deprivation stress model. Eur J Pharmacol 2011, 2-3(658):150-155. 
17. Huang $L Z$, Huang BK, Ye Q: Bioactivity-guided fractionation for antifatigue property of Acanthopanax senticosus. J Ethnopharmacol 2011, 1(133):213-219.

18. Pelkonen $\mathrm{O}$, Urpeinen MT, Hakkola J: Inhibition and induction of human cytochrome P450 enzymes: current status. Arch Toxicol 2008, 10(82):667-715.

19. Gibbson GG, Sheet P: Introduction to Drug Metabolism. London: Blackie Academic and Professional; 1994.

20. Bradford MM: A rapid and sensitive method for the quantitation of microgram quantities of protein utilizing the principle of protein-dye binding. Anal Biochem 1976, 1-2(72):248-254.

21. Bjornsson TD, Callaghan JT, Einolf HJ: The conduct of in vitro and in vivo drug-drug interaction studies: a Pharmaceutical Research and Manufacturers of America (PhRMA) perspective. Drug Metab Dispos 2003, 7(31):815-832

22. Xia $\mathrm{CH}$, Sun JG, Wang GJ: Herb-drug interactions: in vivo and in vitro effect of Shenmai injection, a herbal preparation, on the metabolic activities of hepatic cytochrome P450 3A1/2, 2C6, 1A2, and 2E1 in rats. Planta Med 2009, 3(76):245-250

23. Babbar S, Chanda S, Bley K: Inhibition and induction of human cytochrome P450 enzymes in vitro by capsaicin. Xenobiotica 2010 12(40):807-816.

24. Fayer JL, Petullo DM, Ring BJ: A novel testosterone 6 beta-hydroxylase activity assay for the study of CYP3A-mediated metabolism, inhibition, and induction in vitro. J Pharmacol Toxicol Methods 2002, 2(46):117-123.

25. Khojasteh SC, Prabhu S, Kenny JR: Chemical inhibitors of cytochrome P450 isoforms in human liver microsomes: a re-evaluation of P450 isoform selectivity. Eur J Drug Metab Pharmacokinet 2011, 1(36):11-16.

26. Donovan JL, DeVane CL, Chavin KD: Siberian ginseng (Eleutheroccus senticosus) effects on CYP2D6 and CYP3A4 activity in normal volunteers. Drug Metab Dispos 2003, 5(31):519-522.

27. Martignoni M, Groothuis GM, de Kanter R: Species differences between mouse, rat, dog, monkey and human CYP-mediated drug metabolism, inhibition and induction. Expert Opin Drug Metab Toxicol 2006, 2(6):875-894.

28. Turpeinen M, Ghiciuc C, Opritoui M, Tursas L, Pelkonen O, Pasanen M: Predictive value of animal models for human cytochrome P450 (CYP)mediated metabolism: a comparative study in vitro. Xenobiotica 2007 , 37(12):1367-1377.

29. Obach RS: Inhibition of human cytochrome P450 enzymes by constituents of St. John's Wort. an herbal preparation used in the treatment of depression. J Pharmacol Exp Ther 2000, 1(294):88-95.

30. Winitthana T, Niwattisaiwong N, Patarapanich C: In vitro inhibitory effects of asiaticoside and madecassoside on human cytochrome P450. Toxicol In Vitro 2011, 4(25):890-896.

31. Qiu F, Zhang R, Sun J: Inhibitory effects of seven components of danshen extract on catalytic activity of cytochrome P450 enzyme in human liver microsomes. Drug Metab Dispos 2008, 7(36):1308-1314.

32. Chatterjee $P$, Franklin MR: Human cytochrome $\mathrm{p} 450$ inhibition and metabolic- intermediate complex formation by goldenseal extract and its methylenedioxyphenyl components. Drug Metab Dispos 2003, 11(31):1391-1397.

33. Pekthong $D$, Martin $H$, Abadie C: Differential inhibition of rat and human hepatic cytochrome P450 by Andrographis paniculata extract and andrographolide. Ethnopharmacol 2008, 3(115):432-440.

34. Pandit S, Mukherjee PK, Ponnusankar S: Metabolism mediated interaction of alpha-asarone and Acorus calamus with CYP3A4 and CYP2D6. Fitoterapia 2011, 3(82):369-374.

35. Liu G, Liu Y, Liu R: Effects of Flos carthami on CYP2D6 and on the Pharmacokinetics of Metoprolol in Rats. Evid Based Complement Alternat Med 2011:207076. doi:10.1155/2011/207076.

36. Doehmer J, Weiss G, McGregor GP, Appel K: Assessment of a dry extract from milk thistle (Silybum marianum) for interference with human liver cytochrome-P450 activities. Toxicol In Vitro 2011, 1(25):21-27.

37. Cao Y, Yan X: Study on effects of 36 cases of propofol combined with Acanthopanax Injection for the treatment of insomnia patients. Zhongguo Shi Yong Yi Yao 2011, 14(6):135.

38. Chu X, Liu D: 60 cases of Acanthopanax injection combined with choline injection in the treatment of cervical vertigo. J Tradit Chin Med 2011, 10(20):1699-1700.
39. Gai Y, Zhang T: Clinical study on the effect of Acanthopanax Injection combined with Liposomal Alprostadil in the treatment of stage-IV diabetic nephropathy. J Tradit Chin Med 2011, 4(18):535-537.

40. Du Y: Analysis of literature of 228 cases of adverse drug reactions caused by Acanthopanax Senticosus injection. Zhongguo Lin Chuang Xin Yi Xue 2011, 10(4):946-948.

41. Hu J, Shang H, Li J, Zhang L: 521 cases of adverse drug reactions of Eleutherococcus senticosus Injection based on 944 studies. J Evid Based Med 2010, 2(10):182-188.

doi:10.1186/1472-6882-14-1

Cite this article as: Guo et al:: Effects of Eleutheroside B and

Eleutheroside $\mathrm{E}$ on activity of cytochrome P450 in rat liver microsomes.

BMC Complementary and Alternative Medicine 2014 14:1.

\section{Submit your next manuscript to BioMed Central and take full advantage of:}

- Convenient online submission

- Thorough peer review

- No space constraints or color figure charges

- Immediate publication on acceptance

- Inclusion in PubMed, CAS, Scopus and Google Scholar

- Research which is freely available for redistribution 